\title{
Draft genome sequence of Pseudomonas extremaustralis strain USBA-GBX 515 isolated from Superparamo soil samples in Colombian Andes
}

Gina López ${ }^{1}$, Carolina Diaz-Cárdenas ${ }^{1}$, Nicole Shapiro², Tanja Woyke², Nikos C. Kyrpides², J. David Alzate Laura N. González ${ }^{3}$, Silvia Restrepo ${ }^{3}$ and Sandra Baena ${ }^{1 *}$ (i)

\begin{abstract}
Here we present the physiological features of Pseudomonas extremaustralis strain USBA-GBX-515 (CMPUJU 515), isolated from soils in Superparamo ecosystems, > 4000 m.a.s.l, in the northern Andes of South America, as well as the thorough analysis of the draft genome. Strain USBA-GBX-515 is a Gram-negative rod shaped bacterium of 1.0-3. $0 \mu \mathrm{m} \times 0.5-1 \mu \mathrm{m}$, motile and unable to form spores, it grows aerobically and cells show one single flagellum. Several genetic indices, the phylogenetic analysis of the 16S rRNA gene sequence and the phenotypic characterization confirmed that USBA-GBX-515 is a member of Pseudomonas genus and, the similarity of the 165 rDNA sequence was $100 \%$ with $P$. extremaustralis strain CT14-3 $3^{\top}$. The draft genome of $P$. extremaustralis strain USBA-GBX-515 consisted of $6,143,638 \mathrm{Mb}$ with a $\mathrm{G}+\mathrm{C}$ content of $60.9 \mathrm{~mol} \%$. A total of 5665 genes were predicted and of those, 5544 were protein coding genes and 121 were RNA genes. The distribution of genes into COG functional categories showed that most genes were classified in the category of amino acid transport and metabolism (10.5\%) followed by transcription (8.4\%) and signal transduction mechanisms (7.3\%). We performed experimental analyses of the lipolytic activity and results showed activity mainly on short chain fatty acids. The genome analysis demonstrated the existence of two genes, lip515A and est515A, related to a triacylglycerol lipase and carboxylesterase, respectively. Ammonification genes were also observed, mainly nitrate reductase genes. Genes related with synthesis of poly-hydroxyalkanoates (PHAs), especially poly-hydroxybutyrates (PHBs), were detected. The phaABC and phbABC operons also appeared complete in the genome. P. extremaustralis strain USBA-GBX-515 conserves the same gene organization of the type strain CT14-3 ${ }^{\top}$. We also thoroughly analyzed the potential for production of secondary metabolites finding close to 400 genes in 32 biosynthetic gene clusters involved in their production.
\end{abstract}

Keywords: Pseudomonas extremaustralis, Gammaproteobacteria, Superparamo ecosystems, Psychrophilic soils, 165 rRNA

\section{Introduction}

The genus Pseudomonas, subclass Gammaproteobacteria, is an ubiquitous and metabolically versatile bacterial genera and is currently the genus of Gram-negative bacteria with the largest number of species [1]. Since it first description in 1894 [2], an increasing number of species has been described in diverse environments [3-5]; and now

\footnotetext{
* Correspondence: baena@javeriana.edu.co

${ }^{1}$ Unidad de Saneamiento y Biotecnología Ambiental (USBA), Departamento de Biología, Pontificia Universidad Javeriana, POB 56710, Bogotá, DC, Colombia

Full list of author information is available at the end of the article
}

this genus comprises 255 validly named species, and 13 subspecies, according to the list published in the Namesforlife Database [6]. Psychrophilic environments are the common habitats of the Pseudomonas genus. There are several isolated pseudomonads bacteria from water, freshwater and soils at low temperatures, such as psychrophilic strains of $P$. aeruginosa, $P$. fluorescens, $P$. putida, $P$. syringae, $P$. antarctica, $P$. meridiana and $P$. proteolytica [5, 7-9] and recently $P$. extremaustralis [10]. The type strain of the species $P$. extremaustralis was isolated from a temporary pond in Antarctica [10, 11]. This species presents high levels of oxidative stress and cold resistance 
along with production of high levels of polyhydroxybutyrate (PHB) [11-13]. It is also able to tolerate and to degrade hydrocarbons, allowing it to be used in extreme environments for hydrocarbon bioremediation [14]. The polyhydroxyalkanoate synthase genes are located within a genomic island, which was probably acquired by horizontal gene transfer $[11,12,15]$. Furthermore, P. extremaustralis grows under microaerophilic conditions and forms well developed biofilms that degrades long-chain and branched alkanes, while only medium-chain length alkanes are degraded by planktonic cells [14-16].

The type strain CT14- $3^{\mathrm{T}}$ (DSM 17835) of P. extremaustralis, and its natural derivative, the strain 14-3b (DSM 25547) have been studied for a long time, but no other strains of this species have been reported to our knowledge. We have been involved on microbial diversity studies in the Nevados National Natural Park (Nevados NNP) that harbors different extreme environments, such as permanent snows, superparamo, paramo and thermal springs associated to volcanic activity $[17,18]$. These studies aim to isolate and analyze culture collections of different microbes present in these habitats.

Here we present the physiological features of $P$. extremaustralis strain USBA-GBX-515, isolated from soils in Superparamo ecosystems, in the northern Andes of South America, as well as its draft genome. A genomic comparison with the type strain is also presented.

\section{Organism information}

\section{Classification and features}

Samples were collected in 2010 from Superparamo soil samples within the Nevados NNP at $>4000$ m.a.s.l with soil temperature of $9.8{ }^{\circ} \mathrm{C}$, and $\mathrm{pH}$ of 5.2. Paramo and superparamo are Andean ecosystems in the neotropical high mountain biome [19].

Enrichment was initiated by resuspending $10 \mathrm{~g}$ of rhizospheric soil samples into M9 basal medium (BM) during $30 \mathrm{~m}$ at 150 r.p.m. Then, the cultures were serially diluted, inoculated into M9 BM $\left(10^{-2}\right.$ to $\left.10^{-6}\right)$ and amended with $10 \mathrm{mM}$ tributyrin at $\mathrm{pH} 6.0$, and then incubated at $30{ }^{\circ} \mathrm{C}$ for two weeks. The M9 basal medium contained: $0.5 \mathrm{~g} \mathrm{NaCl}, 3 \mathrm{~g} \mathrm{KH} \mathrm{PO}_{4}, 6 \mathrm{~g} \mathrm{Na}_{2} \mathrm{HPO}_{4}, 1.0 \mathrm{~g}$ $\mathrm{NH}_{4} \mathrm{Cl}$, and $0.05 \mathrm{~g}$ yeast extract. We obtained pure colonies using agar plates with the same medium. Several of the pure isolates obtained were morphologically similar and 16S rRNA genes were 99\% similar among them (data not shown). One strain, designated strain USBA-GBX-515, was selected for this study. The isolated bacterium was stored since the collection date at the Collection of Microorganisms of Pontificia Universidad Javeriana as $P$. extremaustralis strain CMPUJU $\mathbf{5 1 5}$ (CMPUJ, WDCM857). The general features of the strain are reported in Table 1.
Growth was assayed at different pHs (4.5 to 8.5) following the protocols described by Rubiano et al. (2013) [20], with the optimal growth $\mathrm{pH}$ being 7.0. Also, different growth temperatures (from $4{ }^{\circ} \mathrm{C}$ to $35^{\circ} \mathrm{C}$ ) were tested and although growth was observed at all temperatures, the optimum temperature was determined as $30{ }^{\circ} \mathrm{C}$. Strain USBA-GBX-515 is a Gram-negative rod shaped bacterium of 1.0-3.0 $\mu \mathrm{m} \times 0.5-1 \mu \mathrm{m}$ (Fig. 1), aerobic, motile and unable to form spores. Cells present one single flagellum. Colonies are small, smooth, circular and they did not show pigments on Luria Bertani (LB) medium but fluorescent pigments were observed on Centrimide and King B agar. Using the API ZYM strip (BioMérieuxMarcy l'Etoile, France) positive reactions were observed for catalase and oxidase. The API50CH and API 20 (BioMérieux) tests showed positive reactions for L-arginine, sodium citrate and nitrate, nitrite, and negative for starch, casein, urea, indole, D-mannitol, L-arabinose and gelatin. Strain USBAGBX-515 exhibited alkaline phosphatase and phosphohydrolase activities. This strain presents susceptibility to imipenem, piperacilin, ticarcilin, meropenem, levofloxacin, ceftriaxone, cefoxitin and ceftazidime. On the other hand, strain USBA-GBX- $515^{\mathrm{T}}$ showed resistance to penicillin, colistin or polymyxin E, and nitrofurantoin.

Due to our particular interest on lipase enzymes, we also evaluated the lipolytic activity of strain USBA-GBX515 , following the protocols described in [21]. We observed growth on Tween 80, olive oil, triolein, tricaprylin and tributyrin when these compounds were used as carbon sources. We measured the lipolytic activity using $p$-nitrophenyl butyrate during its growth for $42 \mathrm{~h}$ at $30{ }^{\circ} \mathrm{C}$, using tributyrin as carbon source. We detected the maximum activity, $2.0 \mathrm{UL} \mu \mathrm{mol} / \mathrm{L} / \mathrm{min}$ at $15 \mathrm{~h}$ at the end of the exponential phase, as previously reported for the species of the genus [22, 23]. Additionally, we observed the higher activity in the extracellular fraction than in the intracellular fraction.

Analysis for initial phylogenetic inferences was done using universal amplification primers 27F (5' CAG AGTTTGATCCTGGCTCAG 3') and 1492R (5' TACG GYTACCTTGTTACGACTT 3'). PCR products were sequenced using Sanger technology with an eight capillary Applied Biosystems GA-3500 sequencer. Neighborjoining phylogenetic tree reconstruction was done using MEGA 7.0.25. Phylogenetic analysis of the 16S rRNA gene sequence (Fig. 2) confirmed that USBA-GBX-515 is a member of Pseudomonas genus. The most closely related strain was $P$. extremaustralis $\mathrm{CT} 14-3^{\mathrm{T}}$ and then, our isolate was assigned to $P$. extremaustralis, by comparison of the 16S rRNA sequence. Strain USBAGBX- $-515^{\mathrm{T}}$ exhibited a $100 \% 16 \mathrm{~S}$ rRNA sequence identity (e-value $=0.0)$ with $P$. extremaustralis CT14- $3^{\mathrm{T}}$.

P. extremaustralis strain USBA-GBX-515 was stored at the Collection of Microorganisms of Pontificia Universidad 
Table 1 Classification and general features of Pseudomonas extremaustralis strain USBA-GBX 505, according to MIGS standards [24]

\begin{tabular}{|c|c|c|c|}
\hline MIGS ID & Property & Term & Evidence code ${ }^{a}$ \\
\hline & Current classification & Domain: Bacteria & TAS [63] \\
\hline & & Phylum: Proteobacteria & TAS [64] \\
\hline & & Class: Gammaproteobacteria & TAS [65] \\
\hline & & Order: Pseudomonadales & TAS [66] \\
\hline & & Family: Pseudomonadaceae & TAS [67] \\
\hline & & Genus: Pseudomonas & TAS [68] \\
\hline & & Species: Pseudomonas extremaustralis Type strain: $C T 14-3^{\top}$ & TAS [10] \\
\hline & Gram-stain & Negative & IDA \\
\hline & Cell shape & rod-shaped & IDA \\
\hline & Motility & motile & IDA \\
\hline & Sporulation & Negative & IDA \\
\hline & Temperature range & $4{ }^{\circ} \mathrm{C}-35^{\circ} \mathrm{C}$ & IDA \\
\hline & Optimum temperature & $30^{\circ} \mathrm{C}$ & IDA \\
\hline & $\mathrm{pH}$ range; Optimum & $4.5-8.5 ; 7.0$ & IDA \\
\hline & Carbon source & Hexoses & IDA \\
\hline & Energy source & heterotroph & IDA \\
\hline MIGS 6 & Habitat & Super Paramo soil & IDA \\
\hline MIGS 22 & Oxygen requirement & aerobe & IDA \\
\hline MIGS 15 & Biotic relationship & free-living & IDA \\
\hline \multirow[t]{2}{*}{ MIGS 14} & Pathogenicity & & IDA \\
\hline & Biosafety level & unknown & IDA \\
\hline MIGS 4 & Geographic location & La Olleta - Los Nevados National Natural Park & IDA \\
\hline MIGS 5 & Sample collection & 2010 & IDA \\
\hline MIGS 4.1 & Latitude & $045820 \mathrm{~N}$ & IDA \\
\hline MIGS 4.2 & Longitude & $752117 \mathrm{~W}$ & IDA \\
\hline MIGS-4.4 & Altitude & $>4000$ & IDA \\
\hline
\end{tabular}

aEvidence codes: IDA inferred from direct assay (first time in publication); TAS traceable author statement (i.e., a direct report exists in the literature); NAS nontraceable author statement (i.e., not directly observed for the living, isolated sample, but based on a generally accepted property for the species, or anecdotal evidence). These codes are from the Gene Ontology project [69]

Javeriana (CMPUJ, WDCM857) (ID CMPUJ U515) with the ID USBA-GBX 515, growing aerobically on the same medium as mentioned above. Cells were preserved at $-20{ }^{\circ} \mathrm{C}$ in $\mathrm{BM}$ supplemented with $20 \%$ $(v / \mathrm{v})$ glycerol.

\section{Genome sequencing information Genome project history}

The strain was selected to sequencing on the basis of its metabolic versatility and the biotechnological potential as revealed by previous studies [10-12]. This work is part of the bigger study aiming at exploring the microbial diversity in extreme environments in Colombia. More information can be found on the Genomes OnLine database under the study Gs0118134. The JGI accession number is $1,094,800$ and consists of 69 scaffold. Table 2 depicts the project information and its association with MIGS version 2.0 compliance [24]. The USBA-GBX-515 ${ }^{\mathrm{T}}$ draft Genome has the ENA accession number FUYI01000001-FUYI01000069, and is also available through the Integrated Microbial Genomes system under the accession 2,671,180,025.

\section{Growth conditions and genomic DNA preparation} Pseudomonas extremaustralis strain USBA-GBX-515 grew aerobically on LB medium at $30{ }^{\circ} \mathrm{C}$. A $1 \mathrm{~mL}$ of overnight culture was centrifuged for $2 \mathrm{~min}$ at $13000 \mathrm{~g}$. the pellet was immediately used for DNA extraction using the Wizard SV GEnomic DNA purification kit (Promega, USA). The integrity and quality of the DNA was verified using agarose gels (Sigma-Aldrich, St. Louis, USA) $0.8 \%(w / v)$ and using the NanoDropTM system (Thermo Scientific). The genomic DNA concentration was measured by the Qubit ${ }^{\circ}$ dsDNA by fluorometric quantitation (Invitrogen, USA). 


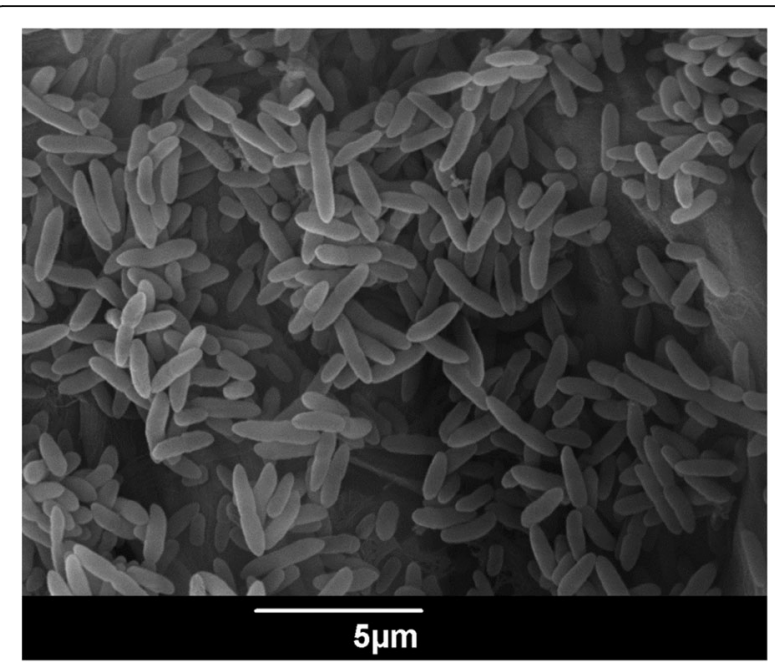

Fig. 1 Scanning electron micrograph of $P$. extremaustralis USBA-GBX515 in exponential phase. The image was obtained under a JSM6490 Scanning Electron Microscope at an operating voltage of $20.0 \mathrm{kV}$, using a modified protocol of Read \& Jeffree [70]. Scale bar represents $5 \mu \mathrm{m}$

\section{Genome sequencing and assembly}

Genomic DNA for Pseudomonas extremaustralis strain USBA-GBX-515 was sequenced on a HiSeq 2500 sequencer (Illumina, SanDiego, CA, USA) with a pairedend strategy (PE150) of 300-bp reads. The sequencing platform generated 10,817,988 reads. After trimming a total of 10,000,000 paired end reads were obtained and assembled into 77 contigs and 69 scaffolds using ALLPATHS [25] and Velvet [26] softwares. All samples were processed using BUSCO [27], which offers a measure for quantitative assessment of genome assembly and annotation quality based on evolutionarily informed expectations of gene content. With the raw data (FastQ read files), the estimated genome size was calculated using different k-mer sizes in Kmergenie [28]. Finally, to obtain assembly metrics of the different genomes, QUAST [29] was run. The draft genome of $P$. extremaustralis strain USBA-GBX-515 consisted of $6,143,638 \mathrm{Mb}$ with a $\mathrm{G}+\mathrm{C}$ content of $60.9 \% \mathrm{~mol}$. Table 3 contains all the genome statistics.

\section{Genome annotation}

Genes were identified using Prodigal [30] as part of the DOE-JGI Annotation pipeline [31, 32]. The predicted CDSs were translated and used to search the National Center for Biotechnology Information (NCBI) nonredundant database, UniProt, TIGRFam, Pfam, PRIAM, KEGG, COG, and InterPro databases. Additional gene prediction analysis and functional annotation was performed within the Integrated Microbial Genomes (IMG-ER) [33].

Biosynthetic clusters were predicted running antiSMASH [34], BAGEL3 [35] and NaPDoS [36]. AntiSMASH was run using the GenBank file generated during annotation from the IMG-ER as the input. Before running the antiSMASH server tool, ClusterFinder algorithm [37], whole-genome PFAM analysis [38] and Enzyme Commission (EC) number prediction were selected. BAGEL3 is a tool specialized in predicting RiPPs and Bacteriocins using as FASTA file as the input.

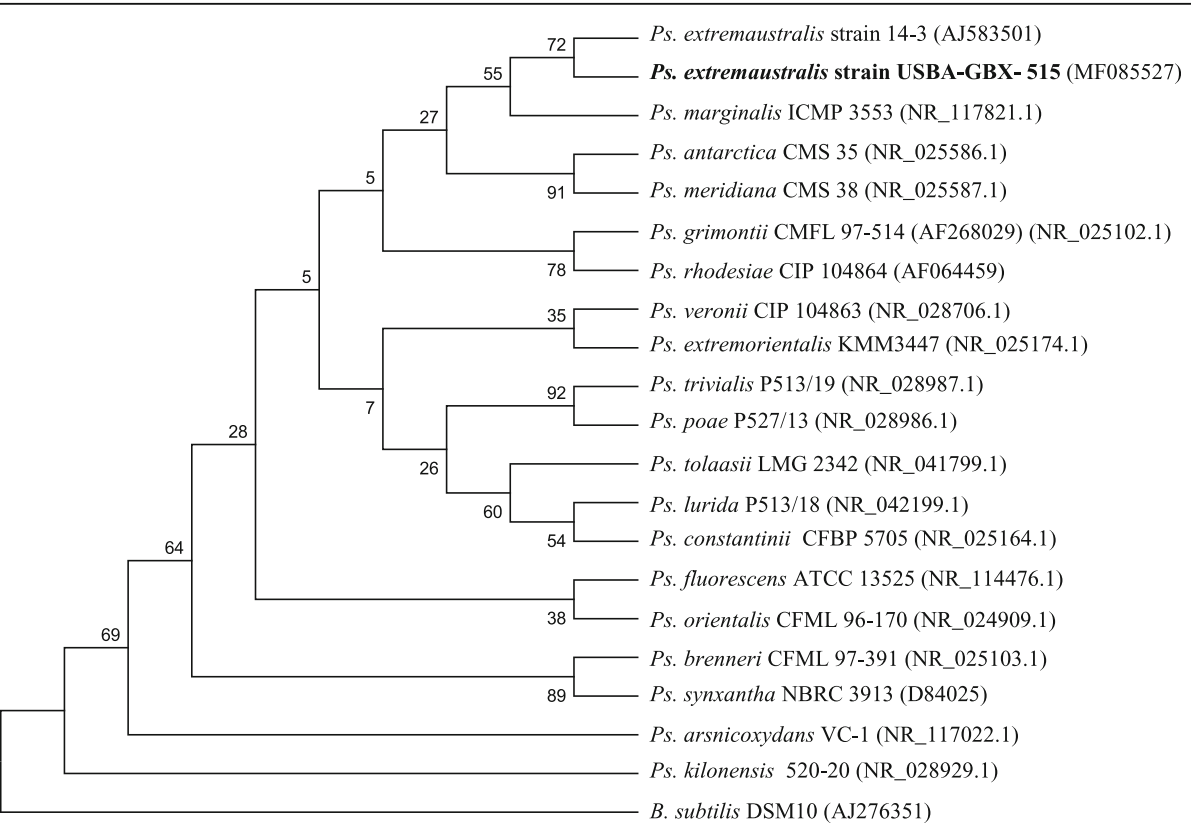

Fig. 2 Phylogenetic tree based on 16S rRNA gene sequences showing the phylogenetic position of Pseudomonas extremaustralis USBA-GBX-515. Bootstrap values were based on 1000 resamplings. Sequence accession numbers are given in parentheses 
Table 2 Project information

\begin{tabular}{lll}
\hline MIGS ID & Property & Term \\
\hline MIGS 31 & Finishing quality & High-quality Draft \\
MIGS 28 & Libraries used & Paired-end \\
MIGS 29 & Sequencing platforms & Illumina HiSeq 2500 \\
MIGS 31.2 & Fold coverage & 239.8 \\
MIGS 30 & Assemblers & ALLPATHS/Nelvet \\
MIGS 32 & Gene calling method & BLAST2GO \\
& Locus Tag & BCL77 \\
& Genbank ID & FUYI01000069.1 \\
& GenBank Date of Release & 04-04-2017 \\
& JGI ID & $1,094,763$ \\
& JGI Date of Release & 02-03-2017 \\
& BIOPROJECT & PRJNA330486 \\
& IMG Taxon ID & $2,671,180,025$ \\
MIGS 13 & Source Material Identifier & USBA 515 \\
& Project relevance & Metabolic versatility, \\
& & natural products discovery \\
& &
\end{tabular}

Finally, the NaPDoS tool was run four times per genome; first with a FASTA nucleotide file as the input and seeking KS domains and second with the same input but seeking $\mathrm{C}$ domains. The third and fourth runs were with FASTA amino acid files, seeking $\mathrm{KS}$ and $\mathrm{C}$ domains respectively. A list of all biosynthetic clusters is available through IMG and IMG-ABC systems [32, 39].

Table 3 Genome statistics

\begin{tabular}{lll}
\hline Attribute & Value & \% of Total \\
\hline Genome size (bp) & $6,143,638$ & 100 \\
DNA coding (bp) & $5,503,417$ & 89.6 \\
DNA G + C (bp) & $3,739,670$ & 60.9 \\
DNA scaffolds & 69 & 100 \\
Total genes & 5665 & 100 \\
Protein coding genes & 5544 & 97.86 \\
RNA genes & 121 & 2.14 \\
Pseudo genes & 60 & 1.06 \\
Genes in internal clusters & 1731 & 30.56 \\
Genes with function prediction & 4524 & 79.86 \\
Genes assigned to COGs & 4091 & 72.22 \\
Genes with Pfam domains & 7255 & 84.70 \\
Genes with signal peptides & 608 & 10.73 \\
Genes with transmembrane helices & 1291 & 22.79 \\
CRISPR repeats & 0 &
\end{tabular}

The total is based on either the size of the genome in base pairs or the total number of protein coding genes in the annotated genome

\section{Genome properties}

The genome of Pseudomonas extremaustralis strain USBA-GBX-515 is $6,143,638$ bp -long with a G+ C content of $60.9 \mathrm{~mol} \%$. A total of 5665 genes were predicted and of those, 5544 were protein coding genes and 121 RNA genes. The properties and statistics of the genome are summarized in Table 3, of the total CDSs, $72.2 \%$ represent COG functional categories. The distribution of genes into COGs functional categories is presented in Table 4. Most genes were classified in the category of amino acid transport and metabolism (10.5\%), followed by transcription (8.38\%) and signal transduction mechanisms (7.3\%).

\section{Insights from the genome sequence}

We performed taxonomic genome comparisons between Pseudomonas USBA-GBX-515 and P. extremaustralis strain $\mathrm{CT} 14-3^{\mathrm{T}}$. The average nucleotide identity (ANI) calculated with the MiSI (Microbial Species Identifier) method [40] is $98.9 \%$ with an Alignment Fraction (AF) of 0.91. Using GGDC web server version 2.1 [41], the DNA-DNA hybridization was calculated, and it showed $96.7 \%$ of similarity; the difference in $\mathrm{G}+\mathrm{C}$ content was less than $1 \%(0.27$ of difference) within both strains. Finally, a pairwise genome alignment performed with Mauve [42] between our strain and the type strain $\mathrm{CT} 14-3^{\mathrm{T}}$ of $P$. extremaustralis $\left(17835^{\mathrm{T}}\right)$ was performed, showing the similarity and conserved synteny of genes (Fig. 3). There are few regions that were unassembled in our genome and those remain in small separated contigs. All analyses corroborate the affiliation of our strain to the species $P$. extremaustralis.

This isolate was screened for lipolytic activities, and the genome analysis showed two genes lip515A and est $515 \mathrm{~A}$ related to a triacylglycerol lipase and carboxylesterase, respectively. Both genes showed a conserved $\alpha / \beta$ hydrolase motif which is common in lipolytic enzymes [43, 44], and are required for the lipids and fatty acid metabolisms. Particularly, the deduced amino acid sequence (296aa) from Gene lip515A showed an identity of $49 \%$ (E value $3 \mathrm{e}-80$ ) with a triacylglycerol lipase from Pseudomonas fragi [45], while gene est515A had a $68 \%$ identity (E value 2 e-85) with a hypothetical protein from Colwellia sp. TT2012.

Ammonification genes were also observed, mainly nitrate reductase genes (narG,H,I,J,L,X and napA). Markers of nitrifying bacteria, nor $B$ and nos $Z$ reductases were found, both genes were described previously in Pseudomonas stutzeri, a nitrate respiring bacterium [46]. We found a norVW gene, which has a role in protection against reactive nitrogen intermediates $[47,48]$. A total of 732 genes were identified to play a role in amino acid transport and metabolism, which depends on nitrogen fixation metabolism. 
Table 4 Number of genes associated with general COG functional categories

\begin{tabular}{|c|c|c|c|}
\hline Code & Value & $\%$ age & Description \\
\hline $\mathrm{E}$ & 511 & 10.95 & Amino acid transport and metabolism \\
\hline G & 247 & 5.29 & Carbohydrate transport and metabolism \\
\hline D & 38 & 0.81 & Cell cycle control, cell division, chromosome partitioning \\
\hline N & 153 & 3.28 & Cell motility \\
\hline M & 266 & 5.7 & Cell wall/membrane/envelope biogenesis \\
\hline B & 2 & 0.04 & Chromatin structure and dynamics \\
\hline H & 237 & 5.08 & Coenzyme transport and metabolism \\
\hline Z & 0 & 0 & Cytoskeleton \\
\hline V & 101 & 2.16 & Defense mechanisms \\
\hline C & 284 & 6.08 & Energy production and conversion \\
\hline W & 31 & 0.66 & Extracellular structures \\
\hline S & 234 & 5.01 & Function unknown \\
\hline $\mathrm{R}$ & 404 & 8.65 & General function prediction only \\
\hline$P$ & 282 & 6.04 & Inorganic ion transport and metabolism \\
\hline U & 116 & 2.49 & Intracellular trafficking, and secretion \\
\hline । & 223 & 4.78 & Lipid transport and metabolism \\
\hline$x$ & 43 & 0.92 & Mobilome: prophages, transposons \\
\hline $\mathrm{F}$ & 106 & 2.27 & Nucleotide transport and metabolism \\
\hline O & 164 & 3.51 & Posttranslational modification, protein turnover, chaperones \\
\hline A & 1 & 0.02 & RNA processing and modification \\
\hline L & 121 & 2.59 & Replication, recombination and repair \\
\hline Q & 133 & 2.85 & Secondary metabolites biosynthesis, transport and catabolism \\
\hline $\mathrm{T}$ & 344 & 7.37 & Signal transduction mechanisms \\
\hline K & 391 & 8.38 & Transcription \\
\hline \multirow[t]{2}{*}{ J } & 236 & 5.06 & Translation, ribosomal structure and biogenesis \\
\hline & 1554 & 27,78 & Not in COG \\
\hline
\end{tabular}

The presence of proline operon $\mathrm{proHJ}$ and proA gene demonstrate the response to high osmolarity due to the de novo synthesis of proline as a stress protectant of the cell [49]. Cell protection from toxic effects of hydrogen peroxide was determined by the presence of the catalase (katE) gene.

Similar to previously observed on $P$. extremaustralis CT14- $3^{\mathrm{T}}$, we found genes related with the synthesis of polyhydroxyalkanoates (PHAs). Especially poly-hydroxybutyrates genes (PHBs), were detected in the bacterial genome using BlastP (e-value $<0.05$ and $90 \%$ coverage of the gene). The phaABC operon was present, containing the PHA synthase (phaC), $\beta$-ketothiolase (phaA), and NADP-dependent acetoacetyl-CoA reductase (phaB). The phbABC operon is also present into the genome, corresponding to the same enzymes.

In order to gain knowledge about the strain USBAGBX- $515^{\mathrm{T}}$, we explored the potential production of secondary metabolites by data mining (Fig. 4). The genes responsible for the secondary metabolites were organized in 32 biosynthetic gene clusters using IMG tools. Those contained approximately 400 genes, the $78 \%$ of clusters were designed as putative, whilst $22 \%$ were related to NRPS and bacteriocin, but it was not possible to identify known metabolites.

Using antiSMASH 3.0 platform we detected 57 cluster of biosynthetic genes. The $56 \%$ of clusters were classified as putative. Two biosynthetic clusters (classified as putative) were assigned to fengycin and alginate clusters. Fengycin is a cyclic lipopeptide acting against phytopathogenic viruses, bacteria, fungi, and nematodes. The lipopeptides are synthesized at modular multienzymatic templates $[50,51]$. The polymer alginate had been identified mainly in the genus Pseudomonas as an exopolysaccharide involved on biofilm formation and pathogenicity [52]. A total of $24.5 \%$ of the clusters were classified as saccharides. Five of the biosynthetic clusters included in this category were related to lipopolysaccharide, pseudopyronine, colonic acid, O-antigen and glidobactin. The proteins coded by the cluster associated 


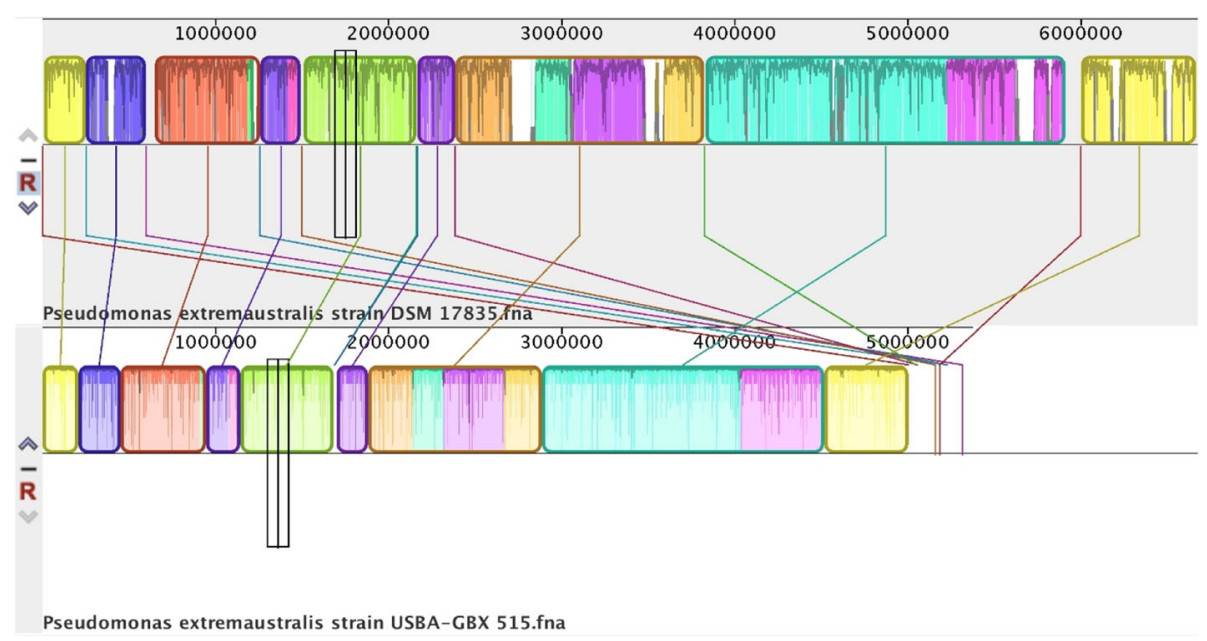

Fig. 3 Multiple Alignment performed using Mauve [42] of $P$. extremaustralis genomes. The type strain $C 114-3^{\top}$ of Pseudomonas extremaustralis (17835 $)$ is shown in the top and the strain USBA-GBX 515 described here at the botton. Conserved blocks are represented with direct lines from type strain to our strain showing synteny of genes among the genome. Small regions between conserved blocks from type strain are

assembled in small contigs at the end of our genome

to lipopolysaccharide (LPS) (Fig. 5) are secreted to the outer surface and the cluster is expressed as a mechanism of resistance to detergents and hydrophobic antibiotics [53]. Colanic acid is an extracellular polysaccharide related to desiccation resistance [54] and to adhesion as pathogenic factor [55] (Fig. 6). O-antigen is a lipopolysaccharide which is associated to adhesion [56] (Fig. 7). The last saccharide cluster is related to glidobactin (Fig. 8), a PKS/NPRS cytotoxic compound which is an antifungal and antitumor antibiotic complex [57]. The

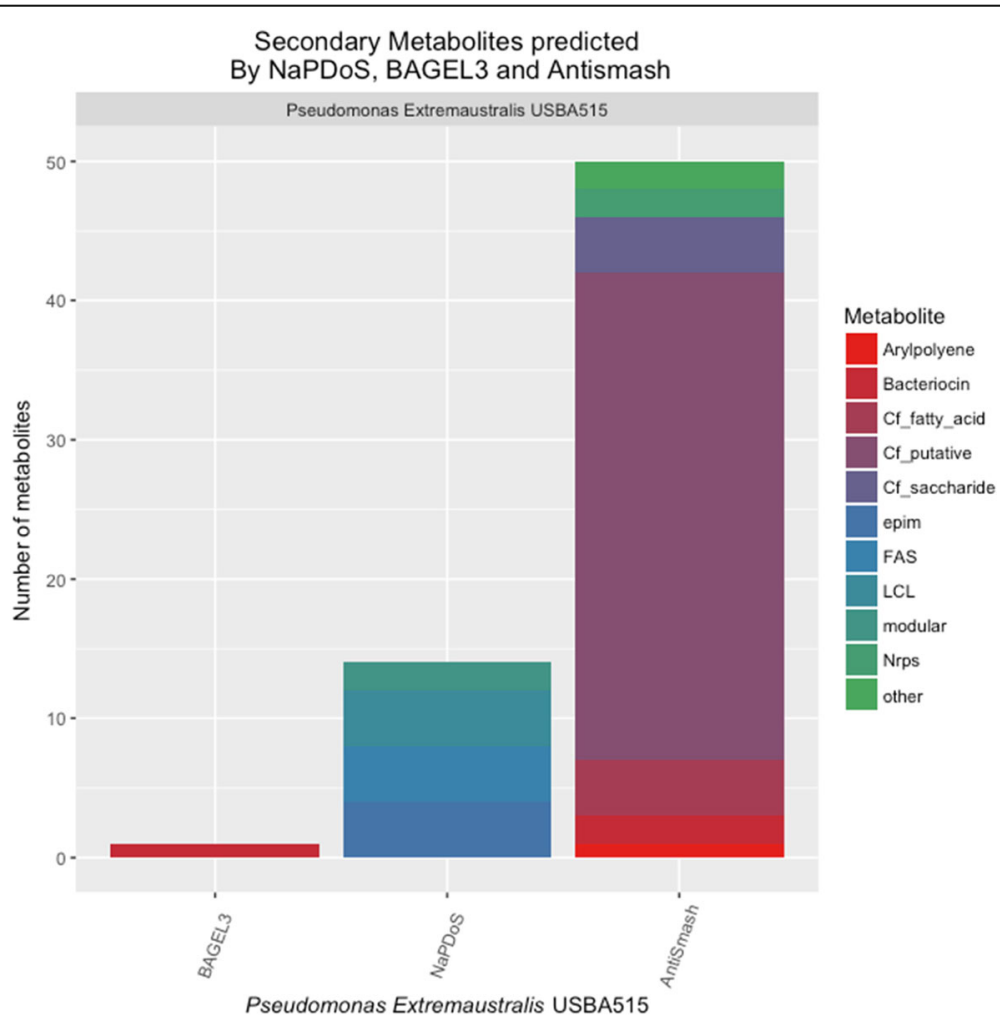

Fig. 4 Secondary metabolites predicted by antiSMASH 3.0 [71], BAGEL3 [35] and NaPDoS [36] softwares in the genome of Pseudomonas extremaustralis strain USBA-GBX-515 


\section{Cluster 1}

Pseudomonas extremaustralis USBA-GBX-515

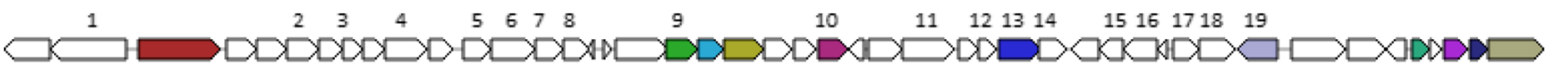

Candidatus Accumulibacter sp. BA-93 ( $9 \%$ of genes show similarity)

109

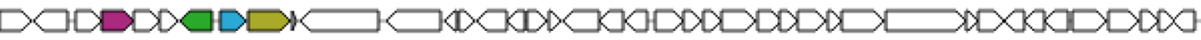

Fig. 5 Genetic map of lipopolysaccharide biosynthetic gene cluster 1 detected by AntiSMASH 3.0. The genes were designated by colors. Same color means equal genes in different strains, not-colored means other genes. 1. pyruvate dehydrogenase subunit E1; 2. UDP-glucose:(heptosyl) LPS alpha 1,3-glucosyltransferase WaaG; 3. hypothetical protein PA5008; 4. Serine/threonine protein kinase; 5. sugar ABC transporter substratebinding protein; 6 . ABC transporter ATP-binding protein; 7. bifunctional carbohydrate binding and transport protein; 8. bifunctional carbohydrate binding and transport protein; 9. glycosyl transferase family protein; 10. glycosyl transferase family protein; 11. lipid A export permease/ATP-binding protein MsbA; 12. adenylyl-sulfate kinase; 13. bifunctional heptose 7-phosphate kinase/heptose 1-phosphate adenyltransferase; 14. Epimerase; 15. hypothetical protein PA4992;16. FAD-dependent oxidoreductase; 17. transcriptional regulator; 18. hypothetical protein PA4974; 19. 3-deoxy-Dmanno-octulosonic acid transferase

\section{Cluster 2}

Pseudomonas extremaustralis USBA-GBX-515

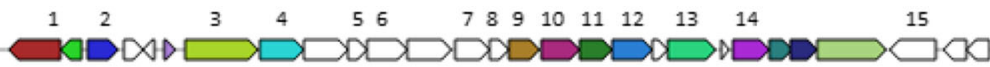

Pseudomonas sp. CF149 (20\% of genes show similarity)

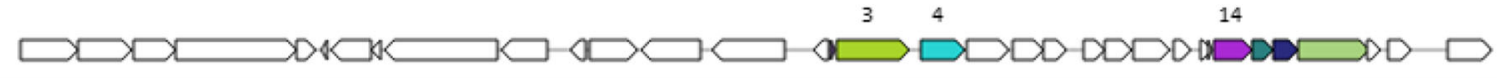

Fig. 6 Genetic map of colanic acid biosynthetic gene cluster 2 detected by AntiSMASH 3.0. The genes were designated by colors. Same color means equal genes in different strains; not colored means other genes. 1. Thiosulfate sulfurtransferase; 2. transcriptional regulator; 3 . nucleotide sugar dehydrogenase; 4. colanic acid production tyrosine-protein kinase; autokinase; Ugd phosphorylase; 5-7. hypothetical protein; 8. putative acyl transferase; 9. Glycosyl transferase; 10. GDP-D-mannose dehydratase, NAD(P)-binding; 11. bifunctional GDP-fucose synthetase: GDP-4-dehydro-6-deoxy-D-mannose epimerase/ GDP-4-dehydro-6-Ldeoxygalactose reductase; 12. colanic acid biosynthesis glycosyl transferase Wcal; 13. mannose-1-phosphate guanylyltransferase/mannose-6-phosphate isomerase

\section{Cluster 3}

Pseudomonas extremaustralis USBA-GBX-515

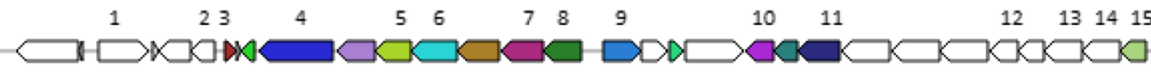

Pseudomonas aeruginosa PA38182 (23\% of genes show similarity)

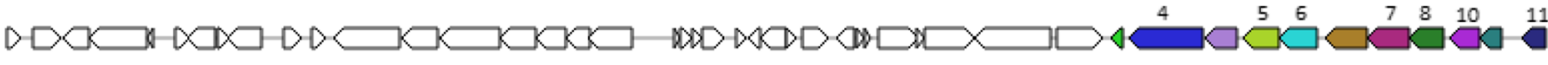

\section{Cluster 4}

Pseudomonas extremaustralis USBA-GBX-515

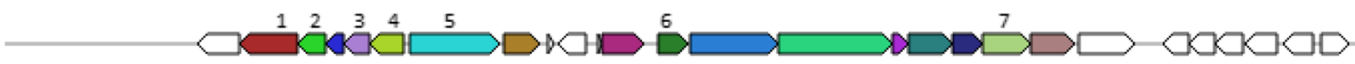

Pseudomonas sp. GM17 PMI20 (30\% of genes show similarity)

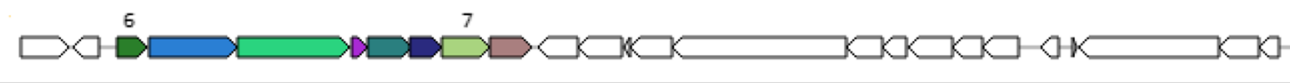

Fig. 7 Genetic map of O-antigen biosynthetic gene cluster 3 and 4 detected by AntiSMASH 3.0. The genes were designated by colors. Same color means equal genes in different strains; not colored means other genes. Cluster 3: 1. Transporter; 2. GntR family transcriptional regulator; 3. TetR family transcriptional regulator; 4. nucleotide sugar epimerase/dehydratase WbpM; 5. NAD-dependent epimerase/dehydratase family protein; 6. glycosyltransferase WbuB; 7. PREDICTED: UDPglucuronic acid decarboxylase 6; 8. bifunctional UDP GlcNAc C6 dehydratase/C5 epimerase PseB; 9. CPS-53 (KpLE1) prophage; bactoprenol glucosyl transferase; 10. imidazole glycerol phosphate synthase subunit HisF; 11. LPS biosynthesis; 12. 3-oxoacyl-ACP reductase; 13. hypothetical protein; 14. pilin glycosylation protein PgIB; 15. mannose-1-phosphate guanyltransferase beta. Cluster 4: 1. two-component sensor; 2. NAD(P)-dependent oxidoreductase; 3. hypothetical protein spr0320; 4. dTDP-D-glucose 4,6-dehydratase; 5. ethanolamine-phosphate phospho-lyase; 6. Epimerase; 7. pellicle/biofilm biosynthesis

glycosyltransferase PelF 


\section{Cluster 5}

Pseudomonas extremaustralis USBA-GBX-515

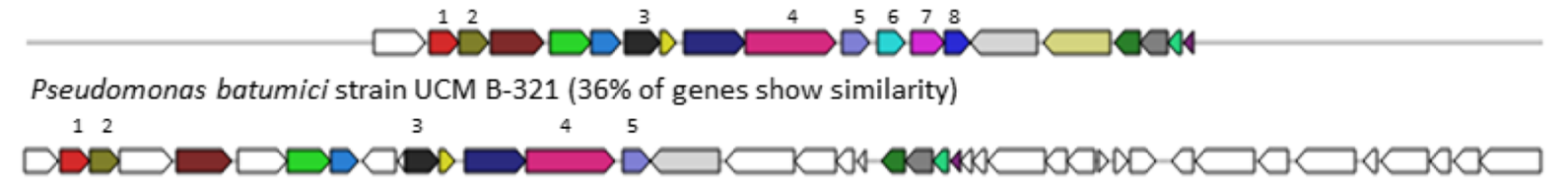

Fig. 8 Genetic map of glidobactin biosynthetic gene cluster 5 detected by AntiSMASH 3.0. The genes were designated by colors. Same color means equal genes in different strains; not colored means other genes. 1. ABC transporter permease; 2. ABC transporter ATP-binding protein; 3. prolyl aminopeptidase; 4. glucan biosynthesis glucosyltransferase; 5. amino acid ABC transporter substrate-binding protein; 6. ABC transporter, PAAT family; 7. ABC transporter permease; 8. $\mathrm{ABC}$ transporter substrate-binding protein

structure of this cluster shows a $36 \%$ similarity to the cluster of "Pseudomonas batumici" strain UCM B-321. A PKS/NRPS compound has been founded from "Pseudomonas batumici" named batumin which exhibits potent and selective antibiotic activity against Staphylococcus species [58]. A biosynthetic gene cluster related to arylpolyene-saccharide was detected (Fig. 9), and this metabolite has a similar structure to a pigment produced by members of the genus Xanthomonas and Flexibacter, which is involved on Gram negative bacteria protection against exogenous oxidative stress [37]. Other clusters were associated to coronatine (Fig. 10) and mangotoxin (Fig. 11) compounds. Both are antimetabolites related to phytotoxins. The coronatine acts as a virulence factor and induces hypertrophy, inhibits root elongation, and stimulates ethylene production [59]. The mangotoxin is a small peptidic molecule, which inhibits the biosynthesis of essential amino acids, resulting in an amino acid deficiency [60]. These toxins could be used as herbicides such as glufosinate and bialaphos, two commercial herbicides that mimic bacterial toxins [60]. Finally, we found a cluster related to pyoverdine (Fig. 12), a nonribosomal peptide siderophore [61].
According to NapDOs program [36], several genes were related to fatty acid biosynthesis, particularly two genes fat478 and fat3803 (related to proteins FabB and FabF, respectively); those proteins are chain elongation condensing enzymes (synthases) that control fatty acid composition and influence the rate of fatty acid production [37].

Using BAGEL3 we found the cluster class III related to S-type Pyocin, a compound with a killing activity causing cell death by DNA breakdown through endonuclease activity [62].

\section{Conclusions}

The strain USBA-GBX-515 isolated from soils associated to superparamo from Andean ecosystems, is a moderate psicrophilic and denitrifier organism. The different genetic indices, the phylogenetic analysis of the $16 \mathrm{~S}$ rRNA gene sequence and the phenotypic characterization confirmed that USBA-GBX-515 belongs to the Pseudomonas extremaustralis species. In addition, the pairwise genome alignment between our strain and the type strain CT14$3^{\mathrm{T}}$ of Pseudomonas extremaustralis $\left(17835^{\mathrm{T}}\right)$ showed

\section{Cluster 6}

Pseudomonas extremaustralis USBA-GBX-515

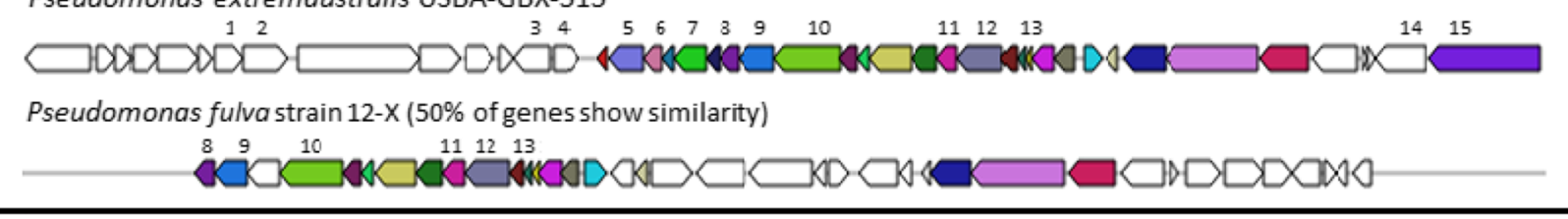

Fig. 9 Genetic map of arylpolyene saccharide biosynthetic gene cluster 6 detected by AntiSMASH 3.0. The genes were designated by colors. Same color means equal genes in different strains, not-colored means other genes. 1. 3-dehydroquinate synthase; 2. hypothetical protein PA5037; 3. major facilitator superfamily transporter; 4. Transcriptional regulator; 5. 3-oxoacyl-(acyl-carrier-protein) synthase II FabF; 6. beta-ketoacyl synthase; 7. SAM-dependent methyltransferase type 11; 8. FAD-binding protein; 9. MMPL family efflux pump permease component. 10. glycosyl transferase; 11 . AMP dependent synthase; 12. acyl carrier protein; 13. Acyltransferase; 14. acyl-CoA dehydrogenase; 15. fused DNA-binding transcriptional regulator/proline

dehydrogenase/pyrroline-5-carboxylate dehydrogenase 


\section{Cluster 7}

Pseudomonas extremaustralis USBA-GBX-515

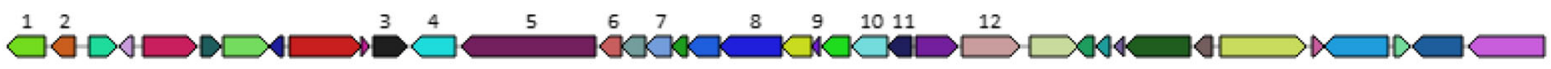

Pseudomonas extremaustralis $14-3$ substr (100\% of genes show similarity)

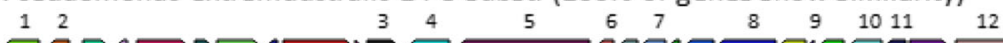

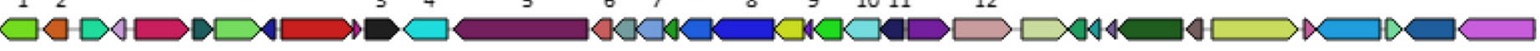

Fig. 10 Genetic map of coronatine biosynthetic gene cluster 7 detected by AntiSMASH 3.0. The genes were designated by colors. Same color means equal genes in different strains; not colored means other genes. 1. hypothetical protein PA4617; 2. quorum-sensing control repressor; 3. Motility regulator; 4. serine hydroxymethyltransferase; 5 . hypothetical protein PA4604; 6. threonine transporter RhtB; 7. Thioesterase; 8. non-ribosomal peptide synthetase; 9. coronamic acid synthetase $\mathrm{CmaD}$; 10. hypothetical protein; 11. transcriptional regulator of proline and 4-hydroxyproline utilization HypR; 12.ABC transporter ATP-binding protein

\section{Cluster 8}

Pseudomonas extremaustralis USBA-GBX-515

Pseudomonas extremaustralis strain $14-3$ (40\% of genes show similarity)

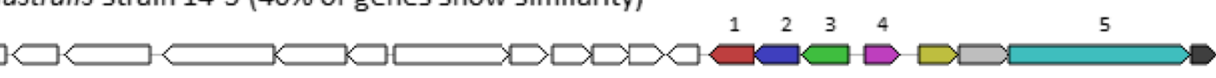

Fig. 11 Genetic map of Mangotoxin biosynthetic gene cluster 8 detected by AntiSMASH 3.0. The genes were designated by colors. Same color means equal genes in different strains; not colored means other genes. 1. ABC transporter permease; 2. ABC transporter ATP-binding protein; 3. hypothetical protein PA2310; 4. transcriptional regulator of proline and 4-hydroxyproline utilization HypR; 5. non-ribosomal peptide synthetase

\section{Cluster 9}

Pseudomonas extremaustralis USBA-GBX-515

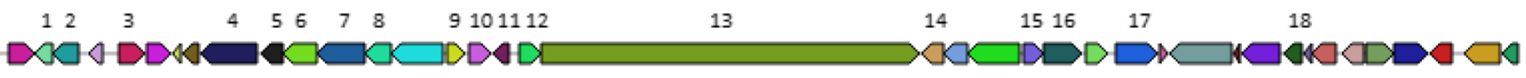

Pseudomonas extremaustralis strain $14-3$ (100\% of genes show similarity)
123
$4 \quad 56 \quad 7 \quad 8$
9101112
13

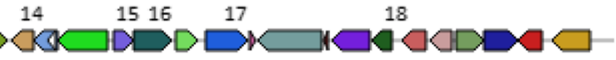

Fig. 12 Genetic map of Pyoverdine biosynthetic gene cluster 9 detected by AntiSMASH. The genes were designated by colors. Same color means equal genes in different strains; not colored means other genes. 1. two-component system response regulator; 2. two-component system response regulator; 3. chemotaxis signal transduction system response regulator CheV; 4. geranyl-CoA carboxylase subunit alpha; 5. Isohexenylglutaconyl-Coa hydratase; 6. citronellyl-CoA dehydrogenase; 7. geranyl-CoA carboxylase subunit beta; 8. citronellol- dehydrogenase; 9. atu genes repressor; 10. amino acid ABC transporter substrate-binding protein; 11. extracytoplasmic-function sigma-70 factor; 12. pyoverdine biosynthesis protein PvdG; 13. Peptide synthase; 14. thiol:disulfide interchange protein DsbG; 15. two-component sensor histidine kinase; 16. two-component response regulator; 17. diaminobutyrate-2-oxoglutarate aminotransferase; 18. pseudouridine synthase 
high similarity and conserved synteny of genes. Based on physiological characterization of this strain, we demonstrated its potential as lipolytic organism. On the other hand, based on a thorough analysis of the genome, we reported this strain as a potential producer of secondary metabolites, such as bactericin pyiocin and PK/NRPS associated to glidobactin, a potential cytotoxic compound. This strain could be also an interesting producer of secondary metabolites such as pyoverdine or glidobactin.

\section{Abbreviations}

CMPUJU: Colección de Microorganismos de la Pontificia Universidad Javeriana; DSM: Deutsche Sammulung von Mikroorganismen; IDA: Inferred from direct assay; m.a.s.l: Meters above sea level; MIGS: Minimum information about a genome sequence; MIGS: Minimum information about a genome sequence; NAS: Non-traceable; PKS/NRPS: Polyketide synthase/non-ribosomal peptide synthetase; TAS: Traceable author statement; WDCM: World Data Center for Microorganisms

\section{Acknowledgments}

This research was funded by Pontificia Universidad Javeriana, Universidad de los Andes, Colciencias-Sena (Project 6570-392-199990), and Colciencias (Project 44842-108-2015). It was done under the Access to Genetic Resources (AGR) contract MAVDT No. 76, 2013 and the research permit No. DTNO-N-20/2007. The work conducted by the U.S. Department of Energy Joint Genome Institute, a DOE Office of Science User Facility, is supported by the Office of Science of the U.S. Department of Energy under Contract No. DE-AC02-05CH11231.

\section{Authors' contributions}

GL carried out the isolation of the strain USBA-GBX-515, physiological studies and analysis of the draft genome. CDC participated in the genomic DNA preparation, physiological studies and analysis of the draft genome. NS, TW and NCK participated in the Genome sequencing, assembly and annotation. JDA and LNG participated in Genome annotation and data mining for secondary metabolites.SR and SB conceived of the study, and participated in its design and coordination and helped to draft the manuscript. All authors read and approved the final manuscript.

\section{Competing interests}

The authors declare that they have no competing interests.

\section{Publisher's Note}

Springer Nature remains neutral with regard to jurisdictional claims in published maps and institutional affiliations.

\section{Author details \\ ${ }^{1}$ Unidad de Saneamiento y Biotecnología Ambiental (USBA), Departamento de Biología, Pontificia Universidad Javeriana, POB 56710, Bogotá, DC, Colombia. ${ }^{2}$ Department of Energy Joint Genome Institute, Joint Genome Institute, Walnut Creek, CA 94598, USA. ${ }^{3}$ Biological Sciences Department, Universidad de los Andes, Cra 1 No. 18A - 12, Bogotá, DC, Colombia.}

Received: 24 May 2017 Accepted: 24 November 2017 Published online: 15 December 2017

\section{References}

1. Gomila M, Peña A, Mulet M, Lalucat J, García-Valdés E. Phylogenomics and systematics in Pseudomonas. Front Microbiol. 2015;6:214.

2. Migula W. In: JV GF, editor. Systemder Bakterien. Handbuck der Morphologie, Entwickelung-Geschichte und Systematik der Bakterien, vol. 1; 1894. p. 235-8.

3. Pietsch RB, Vinatzer BA, Schmale DG. Diversity and abundance of ice nucleating strains of Pseudomonas syringae in a freshwater Lake in Virginia, USA. Front Microbiol. 2017;8:318.

4. Sanchez D, Mulet M, Rodriguez AC, David Z, Lalucat J, et al. Pseudomonas aestusnigri sp. nov., isolated from crude oil-contaminated intertidal sand samples after the prestige oil spill. Syst Appl Microbiol. 2014;37:89-94.
5. Bruni V, Gugliandolo C, Maugeri T, Allegra A. Psychrotrophic bacteria from a coastal station in the Ross sea (Terra Nova Bay, Antarctica). New Microbiol. 1999;22:357-63.

6. Namesforlife. 2017. University Place, Available from: https://www. namesforlife.com/. Accessed July 13, 2017.

7. Shivaji S, Rao NS, Saisree L, Sheth V, Reddy GS, et al. Isolation and identification of Pseudomonas spp. from Schirmacher oasis, Antarctica. Appl Environ Microbiol. 1989;55:767-70.

8. Maugeri TL, Gugliandolo C, Bruni V. Heterotrophic bacteria in the Ross Sea (Terra Nova Bay, Antarctica). New Microbiol. 1996;19:67-76.

9. Reddy GS, Matsumoto Gl, Schumann P, Stackebrandt E, Shivaji S. Psychrophilic pseudomonads from Antarctica: Pseudomonas antarctica sp. nov., Pseudomonas meridiana sp. nov. and Pseudomonas proteolytica sp. nov. Int J Syst Evol Microbiol. 2004;54:713-9.

10. Lopez NI, Pettinari MJ, Stackebrandt E, Tribelli PM, Potter M, et al. Pseudomonas extremaustralis sp nov., a poly(3-hydroxybutyrate) producer isolated from an Antarctic environment. Curr Microbiol. 2009;59:514-9.

11. Ayub ND, Pettinari MJ, Ruiz JA, Lopez NI. A polyhydroxybutyrate-producing Pseudomonas sp. isolated from Antarctic environments with high stress resistance. Curr Microbiol. 2004;49:170-4.

12. Ayub ND, Tribelli PM, Lopez NI. Polyhydroxyalkanoates are essential for maintenance of redox state in the Antarctic bacterium Pseudomonas sp. 143 during low temperature adaptation. Extremophiles. 2009;13:59-66.

13. Raiger lustman LJ, Tribelli PM, Ibarra JG, Catone MV, Solar Venero EC, et al. Genome sequence analysis of Pseudomonas extremaustralis provides new insights into environmental adaptability and extreme conditions resistance. Extremophiles. 2015;19:207-20.

14. Tribelli PM, Di Martino C, Lopez NI, Raiger lustman LJ. Biofilm lifestyle enhances diesel bioremediation and biosurfactant production in the Antarctic polyhydroxyalkanoate producer Pseudomonas extremaustralis. Biodegradation. 2012;23:645-51.

15. Tribelli PM, Mendez BS, Lopez NI. Oxygen-sensitive global regulator, Anr, is involved in the biosynthesis of poly(3-hydroxybutyrate) in Pseudomonas extremaustralis. J Mol Microbiol Biotechnol. 2010;19:180-8.

16. Tribelli PM, Nikel PI, Oppezzo OJ, Lopez NI. Anr, the anaerobic global regulator, modulates the redox state and oxidative stress resistance in Pseudomonas extremaustralis. Microbiology. 2013;159:259-68.

17. Bohorquez LC, Delgado-Serrano L, Lopez G, Osorio-Forero C, Klepac-Ceraj V, et al. In-depth characterization via complementing culture-independent approaches of the microbial community in an acidic hot spring of the Colombian Andes. Microb Ecol. 2012;63:103-15.

18. Delgado-Serrano L, Lopez G, Bohorquez LC, Bustos JR, Rubiano C, et al. Neotropical Andes hot springs harbor diverse and distinct planktonic microbial communities. FEMS Microbiol Ecol. 2014;89:56-66.

19. Madriñán S, Cortés AJ, Richardson JE. Paramo is the world's fastest evolving and coolest biodiversity hotspot. Front Genet. 2013;4:192.

20. Rubiano-Labrador C, Baena S, Díaz-Cárdenas C, Patel BKC. Caloramator quimbayensis sp. nov., an anaerobic, moderately thermophilic bacterium isolated from a terrestrial hot spring. Int J Syst Evol Microbiol. 2013;63: 1396-402.

21. Lopez G, Chow J, Bongen P, Lauinger B, Pietruszka J, et al. A novel thermoalkalostable esterase from Acidicaldus sp. strain USBA-GBX-499 with enantioselectivity isolated from an acidic hot springs of Colombian Andes. Appl Microbiol Biotechnol. 2014;98:8603-16.

22. Ruchi G, Anshu G, Khare SK. Lipase from solvent tolerant Pseudomonas aeruginosa strain: production optimization by response surface methodology and application. Bioresour Technol. 2008;99:4796-802.

23. Wang S-L, Lin Y-T, Liang T-W, Chio S-H, Ming L-J, et al. Purification and characterization of extracellular lipases from Pseudomonas monteilii TKU009 by the use of soybeans as the substrate. J Ind Microbiol Biot. 2009;36:65-73.

24. Field D, Garrity G, Gray T, Morrison N, Selengut J, et al. The minimum information about a genome sequence (MIGS) specification. Nat Biotechnol. 2008;26:541-7.

25. Butler J, MacCallum I, Kleber M, Shlyakhter IA, Belmonte MK, et al. ALLPATHS: de novo assembly of whole-genome shotgun microreads. Genome Res. 2008;18:810-20.

26. Zerbino DR, Birney E. Velvet: algorithms for de novo short read assembly using de Bruijn graphs. Genome Res. 2008;18:821-9.

27. Simão FA, Waterhouse RM, loannidis P, Kriventseva EV, Zdobnov EMBUSCO. Assessing genome assembly and annotation completeness with single-copy orthologs. Bioinformatics. 2015;31:3210-2. 
28. Chikhi R, Medvedev P. Informed and automated k-mer size selection for genome assembly. Bioinformatics. 2014;30:31-7.

29. Gurevich A, Saveliev V, Vyahhi N, Tesler G. QUAST: quality assessment tool for genome assemblies. Bioinformatics. 2013;29:1072-5.

30. Hyatt D, Chen GL, LoCascio P, Land M, Larimer F, et al. Prodigal: prokaryotic gene recognition and translation initiation site identification. BMC Bioinformatics. 2010;11:119.

31. Huntemann M, Ivanova NN, Mavromatis K, Tripp HJ, Paez-Espino D, et al. The standard operating procedure of the DOE-JGI microbial genome annotation pipeline (MGAP v.4). Stand Genomic Sci. 2015;10:86.

32. Chen IA, Markowitz VM, Chu K, Palaniappan K, Szeto E, et al. IMG/M: integrated genome and metagenome comparative data analysis system. Nucleic Acids Res. 2017:45:D507-d516.

33. Markowitz VM, Chen IMA, Palaniappan K, Chu K, Szeto E, et al. IMG: the integrated microbial genomes database and comparative analysis system. Nucleic Acids Res. 2012;40(D1):D115-22.

34. Blin K, Medema MH, Kottmann R, Lee SY, Weber T. The antiSMASH database, a comprehensive database of microbial secondary metabolite biosynthetic gene clusters. Nucleic Acids Res. 2017;45:D555-d559.

35. van Heel AJ, de Jong A, Montalban-Lopez M, Kok J, Kuipers OP. BAGEL3: Automated identification of genes encoding bacteriocins and (non-)bactericidal posttranslationally modified peptides. Nucleic Acids Res. 2013;41:W448-53.

36. Ziemert N, Podell S, Penn K, Badger JH, Allen E, et al. The natural product domain seeker NaPDoS: a phylogeny based Bioinformatic tool to classify secondary metabolite gene diversity. PLoS One. 2012;7:e34064.

37. Cimermancic P, Medema MH, Claesen J, Kurita K, Wieland Brown LC, et al. Insights into secondary metabolism from a global analysis of prokaryotic biosynthetic gene clusters. Cell. 2014;158:412-21.

38. Weber T, Rausch C, Lopez P, Hoof I, Gaykova V, et al. CLUSEAN: a computer-based framework for the automated analysis of bacterial secondary metabolite biosynthetic gene clusters. J Biotechnol. 2009;140:13-7.

39. Hadjithomas M, Chen IA, Chu K, Huang J, Ratner A, et al. IMG-ABC: new features for bacterial secondary metabolism analysis and targeted biosynthetic gene cluster discovery in thousands of microbial genomes. Nucleic Acids Res. 2017:45:D560-d565.

40. Varghese NJ, Mukherjee S, Ivanova N, Konstantinidis KT, Mavrommatis K, et al. Microbial species delineation using whole genome sequences. Nucleic Acids Res. 2015;43:6761-71.

41. Meier-Kolthoff JP, Auch AF, Klenk H-P, Göker M. Genome sequence-based species delimitation with confidence intervals and improved distance functions. BMC Bioinformatics. 2013;14:1-14.

42. Darling AE, Mau B, Perna NT. progressiveMauve: multiple genome alignment with gene gain, loss and rearrangement. PLoS One. 2010;5:e11147.

43. Hausmann S, Jaeger KE, Timmis KN. Lipolytic enzymes from bacteria handbook of hydrocarbon and lipid microbiology. In: Springer Berlin Heidelberg; 2010. pp. 1099-1126.

44. Ramnath L, Sithole B, Govinden R. Classification of lipolytic enzymes and their biotechnological applications in the pulping industry. Can J Microbiol. 2017;63:179-92.

45. Aoyama S, Yoshida N, Inouye S. Cloning, sequencing and expression of the lipase gene from Pseudomonas fragi IFO-12049 in E. coli. FEBS Lett. 1988;242: 36-40.

46. Heiss B, Frunzke K, Zumft WG. Formation of the N-N bond from nitric oxide by a membrane-bound cytochrome bc complex of nitrate-respiring (denitrifying) Pseudomonas stutzeri. J Bacteriol. 1989;171:3288-97.

47. Hutchings Ml, Mandhana N, Spiro S. The NorR protein of Escherichia coli activates expression of the flavorubredoxin gene norV in response to reactive nitrogen species. J Bacteriol. 2002;184:4640-3.

48. Rodionov DA, Dubchak IL, Arkin AP, Alm EJ, Gelfand MS. Dissimilatory metabolism of nitrogen oxides in bacteria: comparative reconstruction of transcriptional networks. PLoS Comput Biol. 2005;1:e55.

49. Brill J, Hoffmann T, Bleisteiner M, Bremer E. Osmotically controlled synthesis of the compatible solute proline is critical for cellular defense of Bacillus subtilis against high osmolarity. J Bacteriol. 2011;193:5335-46.

50. Koumoutsi $A$, Chen $X-H$, Henne A, Liesegang $H$, Hitzeroth $G$, et al. Structural and functional characterization of gene clusters directing nonribosomal synthesis of bioactive cyclic Lipopeptides in Bacillus amyloliquefaciens strain FZB42. J Bacteriol. 2004;186:1084-96.

51. Rehm BHA, Steinbüchel A. Polyhydroxyalkanoate (PHA) synthases: the key enzymes of PHA synthesis. Biopolymers. doi: 10.1002/3527600035.bpol3a06.
52. Schmid J, Sieber V, Rehm B. Bacterial exopolysaccharides: biosynthesis pathways and engineering strategies. Front Microbiol. 2015;6:496.

53. Grozdanov L, Zähringer U, Blum-Oehler G, Brade L, Henne A, et al. A single nucleotide exchange in the wzy gene is responsible for the Semirough 06 lipopolysaccharide phenotype and serum sensitivity of Escherichia coli strain Nissle 1917. J Bacteriol. 2002;184:5912-25.

54. Stevenson G, Andrianopoulos K, Hobbs M, Reeves PR. Organization of the Escherichia Coli K-12 gene cluster responsible for production of the extracellular polysaccharide colanic acid. J Bacteriol. 1996;178:4885-93.

55. Hanna A, Berg M, Stout V, Razatos A. Role of capsular Colanic acid in adhesion of Uropathogenic Escherichia coli. Appl Environ Microbiol. 2003; 69(8):4474-81.

56. Bélanger M, Burrows LL, Lam JS. Functional analysis of genes responsible for the synthesis of the B-band $\mathrm{O}$ antigen of Pseudomonas aeruginosa serotype O6 lipopolysaccharide. Microbiology. 1999;145:3505-21.

57. Schellenberg B, Bigler L, Dudler R. Identification of genes involved in the biosynthesis of the cytotoxic compound glidobactin from a soil bacterium. Environ Microbiol. 2007;9:1640-50.

58. Thistlethwaite IRG, Bull F, Cui C, Walker PD, Gao SS, et al. Elucidation of the relative and absolute stereochemistry of the kalimantacin/batumin antibiotics. Che Sci. 2017:8:6196-201.

59. Couch R, O'Connor SE, Seidle H, Walsh CT, Parry R. Characterization of $\mathrm{CmaA}$, an adenylation-thiolation didomain enzyme involved in the biosynthesis of coronatine. J Bacteriol. 2004;186:35-42.

60. Arrebola E, Cazorla FM, Perez-Garcia A, de Vicente A. Chemical and metabolic aspects of antimetabolite toxins produced by Pseudomonas syringae pathovars. Toxins. 2011;3:1089-110.

61. Calcott MJ, Owen JG, Lamont IL, Ackerley DF. Biosynthesis of novel Pyoverdines by domain substitution in a nonribosomal peptide synthetase of Pseudomonas aeruginosa. Appl Environ Microbiol. 2014;80:5723-31.

62. Michel-Briand $Y$, Baysse $C$. The pyocins of Pseudomonas aeruginosa. Biochimie. 2002;84:499-510.

63. Woese CR, Kandler O, Wheelis ML. Towards a natural system of organisms: proposal for the domains archaea, bacteria, and Eucarya. Proc Nat Acad Sci. 1990;87:4576-9.

64. Garrity GM, Bell JA, Lilburn T: Phylum XIV. Proteobacteria phyl. nov. In: Garrity GM, Brenner D, Krieg N, Staley J, editors. Bergey's Manual of Systematic Bacteriology, Volume 2, Part B. 2nd ed. New York: Springer; 2005: p. 323

65. Garrity GM, Bell JA, Class LT. III. Gammaproteobacteria class. nov. In: Bergey's Manual of Systematics of Archaea and Bacteria, John Wiley \& Sons, Inc. New York: Part B; 2015: p. 1. doi: 10.1002/9781118960608.cbm00045.

66. Garrity M, Bell A, Lilburn T. IX Pseudomonadales Orla-Jensen 1921, 270 AL. Bergey's Manual of Systematic Bacteriology. In: Part two The Proteobacteria. 2nd ed. USA: springer; 2005. p. 384-402.

67. Garrity G, Bell J, Lilburn T. Family I. Pseudomonadaceae. In: KN BDJ, Stanley JT, Garrity GM, editors. Bergey's Manual of Sytematic Bacteriology, The Proteobacteria. New York: Springer; 2005. p. 323.

68. Palleroni NJ. In: Krieg NR, Holt JG, editors. Pseudomonadaceae. Bergey's Manual of Systematic Bacteriology. Baltimore: The Williams and Wilkins Co; 1984. p. 141-99.

69. Ashburner M, Ball CA, Blake JA, Botstein D, Butler H, et al. Gene ontology: tool for the unification of biology. The gene ontology consortium. Nat Genet. 2000:25(1):25-9.

70. Read ND, Jeffree CE. Low-temperature scanning electron microscopy in biology. J Microsc. 1991;161:59-72.

71. Medema MH, Blin K, Cimermancic $P$, de Jager $V$, Zakrzewski $P$, et al. antiSMASH: rapid identification, annotation and analysis of secondary metabolite biosynthesis gene clusters in bacterial and fungal genome sequences. Nucleic Acids Res. 2011:39:W339-46. 